\title{
Sex differences in outcomes and associated factors among stroke patients with small artery occlusion in China
}

Qing Qiao ${ }^{1,2}$, Yan Hong ${ }^{1,2^{*}}$, Wenjuan Zhao ${ }^{1,2}$, Guanen Zhou ${ }^{1,2}$, Qian Liu ${ }^{1,2}$, Xianjia Ning ${ }^{3,4,5}$, Jinghua Wang $3,4,5$ and Zhongping $\mathrm{An}^{1,2^{*}}$

\begin{abstract}
Background: Sex differences in outcomes after small artery occlusion (SAO) stroke have not been well described, particularly in a Chinese population. We aimed to assess sex differences in outcomes and related risk factors among patients with SAO.

Methods: All consecutive patients with SAO were recruited between May 2005 and September 2014. Clinical features and risk factors were recorded. The mortality, recurrence, and dependency rates at 3 months after stroke were assessed.

Results: A total of 2524 patients with SAO were included in this study. There was a higher frequency of mild stroke, current smoking, and alcohol consumption in men than in women. Women were more likely than men to be older, to have diabetes and obesity, and to have higher total cholesterol, high-density lipoprotein cholesterol, and low-density lipoprotein cholesterol levels. There were worse outcomes in men than in women at 3 months after stroke $(P<0.05)$. There were more independent risk factors of poor outcome in men than in women. Older age was a common predictive factor of outcome both in men and in women. In men, low triglyceride levels and high fasting plasma glucose levels were independent risk factors for mortality; in addition, a high low-density lipoprotein cholesterol level was associated with recurrence. Moreover, in men, moderate and severe stroke, and high total cholesterol and fasting plasma glucose levels were risk factors for dependency. A negative association was found between low-density lipoprotein cholesterol level and risk of mortality and between total cholesterol level and risk of recurrence in women.
\end{abstract}

Conclusions: These findings suggest that it is crucial to control conventional risk factors and fasting plasma glucose and lipid levels among patients with SAO, especially male patients, to reduce the burden of stroke in China.

Keywords: Sex differences, Small artery occlusion, Subtypes, Outcomes, Risk factors

\section{Background}

Stroke incidence has declined in developed countries over the past decades, but it has increased in China, becoming the leading cause of death in rural areas and the third leading cause of death in urban areas [1-4]. Furthermore, stroke is now the leading cause of death in China overall, accounting for $>40 \%$ of all-cause deaths [5].

\footnotetext{
* Correspondence: ho_ya1@163.com; tjhhazp@sina.com

${ }^{1}$ Department of Neurology, Tianjin Huanhu Hospital, 6 Jizhao Road, Jinnan

District, Tianjin 300350, China

Full list of author information is available at the end of the article
}

Ischemic stroke is characterized by highly differentiated subtypes $[6,7]$. Small artery occlusion (SAO) is a major ischemic stroke subtype that occurs more commonly in Asian than Western populations [8, 9]. A higher prevalence of small-vessel occlusion was observed in Chinese stroke patients than in Caucasian stroke patients $(33.1 \%$ vs. $19.3 \%)$ [10].

Stroke has a greater impact on women than on men due to the higher longevity in women [11-15]. However, sex differences in outcomes and relevant risk factors among patients with SAO are unclear. Thus, we aimed to assess differences in outcomes and risk factors according to sex

(c) The Author(s). 2018 Open Access This article is distributed under the terms of the Creative Commons Attribution 4.0 International License (http://creativecommons.org/licenses/by/4.0/), which permits unrestricted use, distribution, and reproduction in any medium, provided you give appropriate credit to the original author(s) and the source, provide a link to the Creative Commons license, and indicate if changes were made. The Creative Commons Public Domain Dedication waiver (http://creativecommons.org/publicdomain/zero/1.0/) applies to the data made available in this article, unless otherwise stated. 
among patients with SAO in a large hospital-based stroke registry in China.

\section{Methods}

\section{Patient selection}

This study used data from a stroke registry from three hospitals in Tianjin, China: Tianjin Medical University General Hospital (a university hospital that primarily admits patients from urban areas and patients transferred from rural areas), Tianjin Huanhu Hospital (a neurological specialized hospital that primarily admits patients from urban and rural areas in Tianjin), and Tianjin Haibin People's Hospital (an oilfield staff hospital that primarily admits patients working in the Dagang oilfield and their family members).

All acute ischemic stroke patients diagnosed with SAO according to the Trial of Org 10172 in Acute Stroke Treatment (TOAST) classification from May 2005 to September 2014 were included in this study. In this study, patients who died before the imaging examination and patients with transient ischemic attack were excluded. Information on clinical characteristics and outcomes of all patients with ischemic stroke who were admitted to the stroke units in these three hospitals within $72 \mathrm{~h}$ after stroke onset was collected.

The study was approved by the ethics committee at Tianjin Huanhu Hospital and was found to conform to the Declaration of Helsinki regarding use of human subjects; written informed consent was obtained from each patient during recruitment.

\section{SAO diagnosis criteria}

SAO was diagnosed according to the following criteria [16]: (1) patients presented with one of the traditional clinical lacunar syndromes and no evidence of cerebralcortical dysfunction; (2) the infarction was located in the subcortex or brainstem and was $<1.5 \mathrm{~cm}$ in diameter on computed tomography/magnetic resonance imaging; (3) a previous history of diabetes mellitus (DM) or hypertension supported the clinical diagnosis; (4) potential cardiac embolism was excluded; and (5) $<50 \%$ stenosis in an ipsilateral artery was observed.

\section{Clinical features and risk factors}

Clinical features included stroke subtypes, stroke severity, stroke risk factors, neurological function score, and laboratorial values. Stroke subtypes were classified according to Oxfordshire Community Stroke Project (OCSP) criteria on admission; subtypes included total anterior circulation infarct, partial anterior circulation infarct, lacunar infarct, and posterior circulation infarct (POCI) [17]. Stroke severity was categorized into three groups according to National Institutes of Health Stroke Scale (NIHSS) score: mild (NIHSS score $\leq 7$ ), moderate (NIHSS score 8-16), and severe
(NIHSS score $\geq 17$ ) [18]. Stroke risk factors included hypertension (defined as systolic blood pressure $\geq 140 \mathrm{mmHg}$ / diastolic blood pressure $\geq 90 \mathrm{mmHg}$, self-reported previous history of hypertension, or using antihypertension drugs), DM (defined as fasting plasma glucose $\geq 7 \mathrm{mmol} / \mathrm{L}$, self-reported history of DM, or using hypoglycemic medications at discharge), atrial fibrillation (AF; defined as self-reported history of AF, confirmed by at least one electrocardiogram, or the presence of the arrhythmia during hospitalization), obesity (defined as body mass index $\geq 30 \mathrm{~kg} / \mathrm{m}^{2}$ ), current smoking ( $\geq 1$ cigarette per day for more than 1 year), and alcohol consumption (drinking alcohol at least once per week for more than 1 year).

The NIHSS score, modified Rankin Scale (mRS) score, and Barthel Index (BI) were evaluated on admission, at discharge, and at 3 and 12 months after stroke. Moreover, the fasting levels on admission of total cholesterol (TC), triglycerides (TG), high-density lipoprotein cholesterol (HDL-C), low-density lipoprotein cholesterol (LDL-C), and fasting plasma glucose (FPG) were recorded in this study.

\section{Outcome assessments}

Outcomes included mortality, dependency, and recurrence rates 3 months after stroke. Mortality was defined as all-cause cumulative death at the corresponding follow-up time point. Recurrence was defined as all new-onset vascular events, including stroke, myocardial infarction, and venous thrombosis. Dependency was defined as an mRS score $>2$ [18]. Follow-up was conducted according to a predetermined procedure; the same trained senior neurologist collected data at 3 months. Follow-up was performed for all patients by face-to-face interview, except for patients who were re-examined in their local hospitals, who completed follow-up by telephone (accounted for $2.1 \%$ ).

\section{Management and quality control}

This study was a hospital-based follow-up study. There were three groups overseeing the management of all patients into this stroke registry system. The assessment group consisted of five trained senior neurologists who assessed neurological score during hospitalization. The follow-up group consisted of three senior trained neurologists who performed the reexamination, including evaluating neurological scores, managing risk factors, and directing treatment and rehabilitation. The quality control group consisted of the director of the department of neurology, an epidemiologist, and a data management specialist, who conducted a sampled confirmation for $20 \%$ of all patients every month. 


\section{Stroke treatment}

The most common cause of SAO is hypertension; antihypertensives were prescribed for patients as appropriate. Simultaneously, statins were administered to those with dyslipidemia or evidence of atherosclerosis, and anticoagulants were administered to patients who SAO was caused by AF. Generally, thrombolytic therapy was administered for revascularization within $4 \mathrm{~h}$ of stroke, and antithrombotic therapy and treatment for applicable risk factors (such as hypertension, diabetes, dyslipidemia) were given during the acute stage of stroke.

\section{Statistical analysis}

Continuous variables are presented as means with standard deviations (age and TC, TG, HDL-C, LDL-C, and FPG levels) or as medians with interquartile ranges (NIHSS, BI, mRS) and were compared between men and women using Student's $t$ test or the Mann-Whitney $U$ test. Categorized variables are presented as numbers of cases (rates) and were compared between men and women using the chi-square test. The factors of recurrence were assessed by multivariate stepwise regression after adjusting for covariates (the $P$ value threshold for remaining in the equation was 0.05 , while that for removing the covariate from the equation was 0.10 ); results are presented using adjusted odds ratios (OR) with 95\% confidence intervals (CI). All statistical analyses were performed using SPSS version 19.0 (SPSS Inc., Chicago, IL), and a two-tailed $P$ value $<0.05$ generally indicated statistical significance, but statistical significance in the multivariate analysis was defined as $P$ value $<0.05 /$ number of groups. The thresholds of statistical significance were $P<0.0125$ for OCSP classification and $P<$ 0.0167 for stroke severity.

\section{Results}

Patient selection

A total of 11,330 patients with acute ischemic stroke were recruited during the study period, and 2524 patients with SAO were included in this study after excluding 8679 non-SAO patients and 127 patients without TOAST classification data. The response rate was $98.9 \%$ 3 months after stroke. Moreover, there were 27 SAO patients (1.1\%) lost to follow-up 3 months after stroke. We excluded these patients from the analysis (Fig. 1).

\section{Sex differences in clinical features among patients with SAO} Of these patients with SAO, there were 1696 men $(67.2 \%)$ and 828 women (32.8\%), with mean ages of 64.10 years overall, 61.93 years for men, and 65.62 years for women $(P<0.001)$. Men were more likely than women to be $<75$ years $(84.6 \%$ vs. $79.6 \%)$, have mild stroke $(84.1 \%$ vs. $79.6 \%)$, smoke $(50.4 \%$ vs. $12.0 \%)$, and consume alcohol (27.1\% vs. $1.8 \%$; all $P<$ 0.001 ). The prevalence rates of DM and obesity were higher in women than in men. Moreover, women had worse neurological function than men on admission, and average TC, HDL-C, and LDL-levels $\mathrm{C}$ were higher in women than in men (Table 1).

\section{Sex differences in outcomes among patients with SAO}

As shown in Table 2, there were worse outcomes in men than in women 3 months after stroke, with mortality, recurrence, and dependency rates of $1.9 \%, 3.8 \%$, and $8.9 \%$ in men and $0.6 \%, 1.7 \%$, and $6.2 \%$ in women, respectively $(P<0.05)$.

\section{Sex differences in factors associated with outcomes among patients with SAO in the multivariate stepwise regression analysis}

In the multivariate analysis, the hazard of mortality 3 months after stroke was associated with older age,

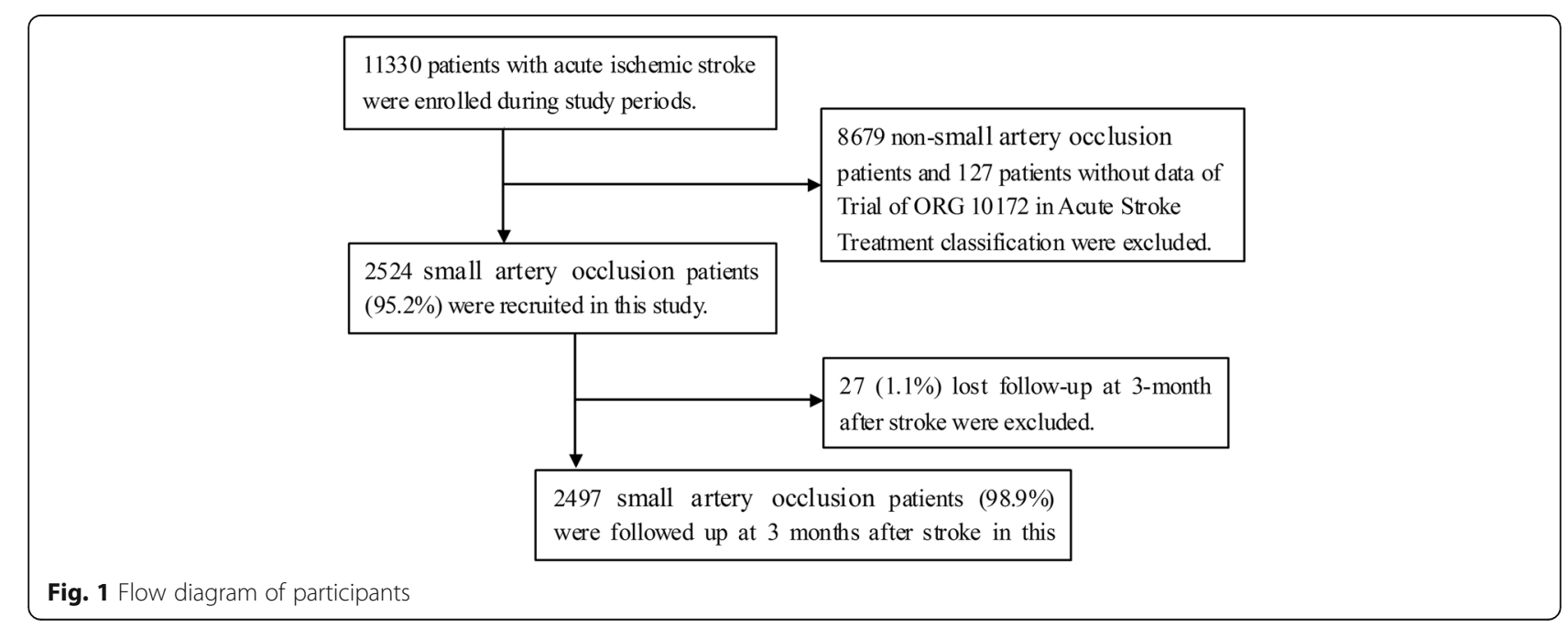


Table 1 Sex differences in clinical features and risk factors among patients with SAO

\begin{tabular}{|c|c|c|c|c|c|}
\hline Characteristics & $\begin{array}{l}\text { Men } \\
(n=1696)\end{array}$ & Women $(n=828)$ & $t / x^{2}$ & df & $P$ \\
\hline Age, years, means (SD) & $61.93(11.41)$ & $65.62(10.86)$ & 7.736 & 2522 & $<0.001$ \\
\hline Age group, $n(\%)$ & & & 34.828 & 1 & $<0.001$ \\
\hline$<75$ years & 1435 (84.6) & $620(74.9)$ & & & \\
\hline$\geq 75$ years & $261(15.4)$ & $208(25.1)$ & & & \\
\hline \multicolumn{6}{|l|}{ OCSP classification, n (\%) } \\
\hline $\mathrm{PACl}$ & $642(37.9)$ & $354(42.8)$ & 5.592 & 1 & ns \\
\hline TAPI & $30(1.8)$ & $13(1.6)$ & 0.131 & 1 & ns \\
\hline $\mathrm{LACl}$ & $473(27.9)$ & $220(26.6)$ & 0.486 & 1 & ns \\
\hline $\mathrm{POCl}$ & $551(32.5)$ & $241(29.1)$ & 2.955 & 1 & ns \\
\hline \multicolumn{6}{|l|}{ Stroke severity*, $n$ (\%) } \\
\hline Mild & $1427(84.1)$ & $656(79.6)$ & 7.930 & 1 & 0.005 \\
\hline Moderate & $234(13.8)$ & $141(17.1)$ & 4.810 & 1 & ns \\
\hline Severe & $35(2.1)$ & $27(3.3)$ & 3.400 & 1 & ns \\
\hline \multicolumn{6}{|l|}{ Risk factors, $n$ (\%) } \\
\hline Hypertension & $1278(75.4)$ & $638(77.1)$ & 0.879 & 1 & ns \\
\hline Diabetes & $514(30.3)$ & 303 (36.6) & 10.048 & 1 & 0.002 \\
\hline Atrial fibrillation & $41(2.4)$ & $18(2.2)$ & 0.145 & 1 & ns \\
\hline Obesity & $139(8.2)$ & $152(18.4)$ & 56.325 & 1 & $<0.001$ \\
\hline Current smoking & $854(50.4)$ & $99(12.0)$ & 349.041 & 1 & $<0.001$ \\
\hline Alcohol drinking & $459(27.1)$ & $15(1.8)$ & 232.599 & 1 & $<0.001$ \\
\hline \multicolumn{6}{|l|}{ Neurological function ${ }^{\dagger}$} \\
\hline NIHSS & $4(4)$ & $4(5)$ & 15.928 & 1 & $<0.001$ \\
\hline $\mathrm{mRS}$ & $2(3)$ & $3(3)$ & 12.908 & 1 & $<0.001$ \\
\hline $\mathrm{Bl}$ & $75(45)$ & $70(45)$ & 33.129 & 1 & $<0.001$ \\
\hline \multicolumn{6}{|c|}{ Laboratory testing, mmol/L, means (SE) } \\
\hline FPG & $6.37(2.72)$ & $6.58(2.73)$ & 1.633 & 1954 & ns \\
\hline $\mathrm{TC}$ & $4.74(0.95)$ & $5.23(1.04)$ & 11.291 & 2423 & $<0.001$ \\
\hline TG & $1.64(0.99)$ & $1.71(0.96)$ & 1.153 & 2423 & ns \\
\hline $\mathrm{HDL}-\mathrm{C}$ & $1.04(0.59)$ & $1.15(0.29)$ & 4.650 & 2407 & $<0.001$ \\
\hline LDL-C & $2.92(0.78)$ & $3.15(0.83)$ & 6.594 & 2405 & $<0.001$ \\
\hline
\end{tabular}

*There were 4 female patients for whom NIHSS scores were not obtained

${ }^{\dagger}$ Data presented as medians with interquartile ranges

Table 2 Sex differences in outcomes 3 months after stroke among patients with SAO

\begin{tabular}{llllll}
\hline Outcomes & Men & Women & $t / x^{2}$ & df & $P$ \\
\hline Mortality, $n$ (\%) & & & 6.338 & 1 & 0.012 \\
Numbers for followed-up & 1678 & 819 & & & \\
Death case & $32(1.9)$ & $5(0.6)$ & & & \\
Recurrence, $n$ (\%) & & & 7.571 & 1 & 0.006 \\
Numbers for followed-up & 1646 & 812 & & & \\
Recurrent case & $62(3.8)$ & $14(1.7)$ & & & \\
Dependency, $n$ (\%) & & & 5.469 & 1 & 0.019 \\
Numbers for followed-up & 1678 & 819 & & & \\
Dependency case & $150(8.9)$ & $51(6.2)$ & & & \\
\hline
\end{tabular}

moderate stroke, low TG level, and elevated FPG level in men. Older age and elevated LDL-C level were independent risk factors for recurrence, with ORs $(95 \% \mathrm{CIs})$ of $1.04(1.01,1.07 ; P=0.008)$ for age and $1.80(1.25,2.60$; $P=0.002)$ for LDL. Moreover, older age, moderate and severe stroke, and high TC and FPG levels were risk factors for dependency 3 months after stroke. In women, older age was a common risk factor of recurrence and dependency 3 months after stroke. Moreover, LDL-C level was associated with mortality 3 months after SAO, and TC level was independently associated with recurrence (Table 3). 
Sex differences in clinical features and risk factors among patients with large artery atherothrombosis (LAA)

Table 4 displays the sex differences in clinical features, risk factors, and outcomes 3 months after stroke among patients with LAA. Similar to the findings with SAO, male patients with LAA were more likely than female patients to have mild stroke, smoke, and drink alcohol; female patients with LAA were more likely than male patients to be older and have DM, obesity, poor neurological function, and high TC, HDL-C, and LDL-C levels (all $P<0.05$ ). In contrast to the findings with SAO, male patients with LAA were more likely than female patients to have POCI; the frequency of POCI was $37.1 \%$ in men and $33.4 \%$ in women $(P=0.002)$. Female patients with LAA were more likely than male patients to have severe stroke $(12.3 \%$ vs. $9.3 \% ; P<0.001)$, hypertension $(77.1 \%$ vs. $75.4 \%$ ), and high FPG and TG levels (all $P<0.001$ ). Moreover, there were significant sex differences in dependency rates 3 months after stroke among patients with LAA.

\section{Discussion}

This is the first report to describe sex differences in outcomes and relevant risk factors among patients with SAO. We demonstrated that mortality, recurrence, and dependency rates 3 months after stroke were significantly higher in men than in women. Older age was a common risk factor of outcomes both in men and in women. Low TG level and high FPG level were independent risk factors for mortality; high LDL-C level were associated with recurrence in men. Moreover, in men, moderate and severe stroke, and high TC and FPG levels were risk factors for dependency. Negative associations were found between LDL-C level and the risk of mortality and between TC level and the risk of recurrence. Inconsistent with the findings for SAO, there were no significant sex differences in mortality and recurrence rates 3 months after stroke among patients with LAA.

The prevalence rates of small-vessel occlusion and internal carotid artery stenosis are high in Asian countries [8]. However, there are limited reports on SAO; moreover, the reported outcomes among patients with SAO have been controversial. Most previous studies demonstrated favorable short-term outcomes among SAO patients $[19,20]$ and favorable long-term outcomes among elderly SAO patients $[17,21]$. Moreover, young patients with SAO experienced low mortality rates over a 5-year follow-up period [22]. In contrast to these studies, a 10-year follow-up study reported a worse prognosis for those with lacunar stroke compared to the general population [23].

Distinct from previous studies, in the present study, we assessed sex differences in clinical features, outcomes, and associated factors among SAO patients. We found that mortality, recurrence, and dependency rates were higher in men than in women. There were poor outcomes in men 3 months after stroke. Simultaneously, lower prevalence rates of DM and obesity were observed in male SAO patients.

A few studies have investigated the association between DM and the long-term prognosis of patients after acute ischemic stroke [24, 25]; however, the evidence for this association remains controversial. A report from

Table 3 Factors associated with outcomes 3 months after stroke among male and female patients with SAO by multiple stepwise regression analysis

\begin{tabular}{|c|c|c|c|c|c|c|c|c|c|c|c|c|c|}
\hline \multirow[t]{2}{*}{ Risk factors } & \multirow[t]{2}{*}{ Reference } & \multicolumn{4}{|l|}{ Mortality } & \multicolumn{4}{|l|}{ Recurrence } & \multicolumn{4}{|l|}{ Dependency } \\
\hline & & OR (95\%Cl) & $x^{2}$ & df & $P$ & OR $(95 \% \mathrm{Cl})$ & $x^{2}$ & df & $P$ & OR $(95 \% \mathrm{Cl})$ & $x^{2}$ & df & $P$ \\
\hline \multicolumn{14}{|l|}{ Men } \\
\hline Age & - & $1.06(1.02,1.11)$ & 7.287 & 1 & 0.023 & $1.04(1.01,1.07)$ & 6.804 & 1 & 0.008 & $1.05(1.03,1.07)$ & 20.397 & 1 & $<0.001$ \\
\hline Severity & Mild & & & & & & & & & & & & \\
\hline Moderate & & $4.21(1.59,11.18)$ & 8.332 & 1 & 0.004 & - & & & - & $2.45(1.48,4.05)$ & 12.189 & 1 & $<0.001$ \\
\hline Severe & & $2.88(0.31,26.91)$ & 0.913 & 1 & 0.355 & - & & & - & $5.21(1.68,16.09)$ & 8.209 & 1 & 0.004 \\
\hline Obesity & No & & & & & & & & & $0.39(0.15,1.01)$ & 3.727 & 1 & 0.054 \\
\hline $\mathrm{TC}$ & - & - & & & & - & & & - & $1.33(1.07,1.64)$ & 7.574 & 1 & 0.009 \\
\hline TG & - & $0.27(0.10,0.72)$ & 6.894 & 1 & 0.009 & - & & & - & - & & & - \\
\hline LDL-C & - & & & & & $1.80(1.25,2.60)$ & 9.837 & 1 & 0.002 & & & & \\
\hline FPG & - & $1.46(1.27,1.67)$ & 28.388 & 1 & $<0.001$ & - & & & - & $1.16(1.09,1.24)$ & 19.466 & 1 & $<0.001$ \\
\hline \multicolumn{14}{|l|}{ Women } \\
\hline Age & - & - & & & - & $1.06(1.02,1.09)$ & 10.539 & 1 & 0.001 & $1.05(1.02,1.08)$ & 10.047 & 1 & 0.002 \\
\hline $\mathrm{TC}$ & - & & & & & $0.67(0.46,0.97)$ & 4.489 & 1 & 0.034 & & & & \\
\hline LDL-C & - & $0.15(0.03,0.78)$ & 5.086 & 1 & 0.024 & & & & & & & & \\
\hline
\end{tabular}


Table 4 Sex differences in clinical features and risk factors among patients with LAA

\begin{tabular}{|c|c|c|c|c|c|}
\hline Characteristics & $\begin{array}{l}\text { Men } \\
(n=1696)\end{array}$ & $\begin{array}{l}\text { Women } \\
(n=828)\end{array}$ & $t / x^{2}$ & $d f$ & $P$ \\
\hline Age, years, means (SD) & $62.79(11.52)$ & $67.26(10.38)$ & 16.348 & 7598 & $<0.001$ \\
\hline Age group, $n(\%)$ & & & 69.098 & 1 & $<0.001$ \\
\hline$<75$ years & $4171(81.4)$ & $1808(73.1)$ & & & \\
\hline$\geq 75$ years & 954 (18.6) & $667(26.9)$ & & & \\
\hline \multicolumn{6}{|l|}{ OCSP classification, $n$ (\%) } \\
\hline $\mathrm{PACl}$ & $2927(57.1)$ & $1509(61.0)$ & 10.220 & 1 & 0.001 \\
\hline TAPI & $279(5.4)$ & $127(5.1)$ & 0.323 & 1 & ns \\
\hline $\mathrm{LACl}$ & $20(0.4)$ & $12(0.5)$ & 0.356 & 1 & ns \\
\hline $\mathrm{POCl}$ & $1899(37.1)$ & $827(33.4)$ & 9.611 & 1 & 0.002 \\
\hline \multicolumn{6}{|l|}{ Stroke severity, $n(\%)$} \\
\hline Mild & $3262(63.7)$ & 1419 (57.3) & 28.251 & 1 & $<0.001$ \\
\hline Moderate & $1386(27.0)$ & $752(30.4)$ & 7.342 & 1 & $<0.001$ \\
\hline Severe & $476(9.3)$ & $304(12.3)$ & 16.233 & 1 & $<0.001$ \\
\hline \multicolumn{6}{|l|}{ Risk factors, $n(\%)$} \\
\hline Hypertension & $1278(75.4)$ & $638(77.1)$ & 104.860 & 1 & $<0.001$ \\
\hline Diabetes & $1576(30.8)$ & $957(38.7)$ & 47.060 & 1 & $<0.001$ \\
\hline Atrial fibrillation & $181(3.5)$ & $133(5.4)$ & 14.297 & 1 & $<0.001$ \\
\hline Obesity & $471(9.2)$ & $508(20.5)$ & 191.082 & 1 & $<0.001$ \\
\hline Current smoking & $2704(52.8)$ & $374(15.1)$ & 981.771 & 1 & 0.002 \\
\hline Alcohol drinking & $1448(28.3)$ & $25(1.0)$ & 792.793 & 1 & $<0.001$ \\
\hline \multicolumn{6}{|c|}{ Neurological function, median (interquartile range) } \\
\hline $\mathrm{NIHSS}$ & $6(7)$ & $6(8)$ & 36.511 & 1 & 0.001 \\
\hline mRS & $3(2)$ & $4(6)$ & 51.413 & 1 & $<0.001$ \\
\hline $\mathrm{Bl}$ & $60(50)$ & $50(50)$ & 62.025 & 1 & $<0.001$ \\
\hline \multicolumn{6}{|c|}{ Laboratory value, mmol/L, means (SE) } \\
\hline FPG & $6.50(2.67)$ & $6.91(2.86)$ & 5.376 & 5733 & $<0.001$ \\
\hline $\mathrm{TC}$ & $4.76(1.04)$ & $5.233(1.15)$ & 21.085 & 7253 & $<0.001$ \\
\hline TG & $1.58(1.00)$ & $1.74(1.27)$ & 5.808 & 7253 & $<0.001$ \\
\hline $\mathrm{HDL}-\mathrm{C}$ & $1.02(0.27)$ & $1.14(0.31)$ & 16.734 & 7210 & $<0.001$ \\
\hline LDL-C & $2.96(0.84)$ & $3.27(0.91)$ & 13.989 & 7203 & $<0.001$ \\
\hline \multicolumn{6}{|c|}{ Prognosis at 3 months after stroke, $n(\%)$} \\
\hline Mortality & $355(7.1)$ & $194(8.0)$ & 2.011 & 1 & ns \\
\hline Recurrence & $194(4.2)$ & $89(4.0)$ & 0.107 & 1 & ns \\
\hline Dependency & $753(15.0)$ & 416 (17.2) & 5.604 & 1 & 0.018 \\
\hline
\end{tabular}

China demonstrated that DM independently predicted poor outcomes within 6 months in Chinese patients after acute ischemic stroke [26]. Several studies have reported that DM was associated with a higher stroke mortality rate $[27,28]$, but this was not observed in other studies [29, 30]. Furthermore, many studies have indicated that $\mathrm{DM}$ is an important predictive factor for dependency [28, 31, 32] and recurrence rates [33-35]. However, several studies have shown no remarkable relationship between DM and stroke prognosis $[27,29,36]$. In addition, one study reported that a lower neurological deficit at admission was observed in stroke patients with DM [37]. A recent study indicated that elevated glycosylated hemoglobin level on admission was adversely associated with functional outcomes 3 months after stroke among patients with SAO [38]; both fasting glucose and DM were associated with an increased risk of stroke in patients diagnosed with a minor stroke or transient ischemic attack [39]. 
In this study, we found no association in men or women between a previous history of DM and stroke outcome; however, FPG level was positively associated with mortality and dependency in male SAO patients. Moreover, while we found a higher prevalence of DM in women than in men, women had lower mortality, recurrence, and dependency rates. The effective management and control of FPG levels in patients with DM can improve outcomes for female stroke patients, and this may have contributed to the lower risk of poor outcomes among female SAO patients in this study.

Furthermore, the relationship between lipid levels and outcomes among SAO patients remains unclear. In a hospital-based study, low serum TC levels were associated with poor functional outcomes in ischemic stroke patients who had received pre-stroke statin treatment, and the short-term and long-term mortality rates were significantly higher in patients with low cholesterol levels [40]. However, our previous findings suggested that there was no significant association between low cholesterol levels and mortality after stroke [41].

In the present study, among male SAO patients, a positive association between TC level and dependency 3 months after stroke was observed, but there was a negative association between TG level and mortality 3 months after stroke. Statins might have a neuroprotective effect [42-44], but the timeliness of statin therapy may explain why the high TC level increased the risk of dependency among SAO patients 3 months after stroke. A long-term follow-up study is needed in the future to explore the impact of TC on outcomes of SAO patients.

There were several limitations in this study. First, this study was conducted in Tianjin, China, and thus represents a limited population. Second, information regarding medication usage before stroke onset was lacking, and this may have affected evaluation of the association between risk factors and outcomes. Finally, all patients were recruited from stroke units; patients with fatal strokes or silent strokes were excluded from this study, and this could have impacted the assessment of outcomes.

\section{Conclusion}

This is the first report to describe sex differences in outcomes and relevant determinants among patients with SAO. We demonstrated that mortality, recurrence, and dependency rates 3 months after stroke were significantly higher in men than in women. Older age, severe stroke, and high FPG level were independent risk factors for mortality and dependency in men. Moreover, in men, TG level was negatively associated with mortality, TC level was positively associated with dependency, and LDL-C level was an independent risk factor for recurrence. A negative association between $\mathrm{LDL}-\mathrm{C}$ level and mortality was found in women. In addition, older age was positively associated with the risk of recurrence and dependency in women, and TC level was negatively associated with the risk of recurrence. These findings suggest that it is crucial to address the management of FPG and TC levels among patients with SAO, especially male patients, to reduce the burden of stroke in China.

\section{Abbreviations}

BI: Barthel index; Cl: Confidence intervals; DM: Diabetes mellitus; FPG: Fasting plasma glucose; HDL-C: High-density lipoprotein cholesterol; LAA: Large artery atherothrombosis; LDL-C: Low-density lipoprotein cholesterol; mRS: Modified Rankin Scale; NIHSS: National Institutes of Health Stroke Scale: OCSP: Oxfordshire community stroke project; OR: Odds ratios; POCI: Posterior circulation infarct; SAO: Small artery occlusion; TC: Total cholesterol; TG: Triglycerides; TOAST: Trial of Org 10172 in acute stroke treatment

\section{Acknowledgements}

We thank all participants in this study.

\section{Funding}

This study was funded by Tianjin Health Bureau of Science and Technology Fund Key Projects (contract: 16KG160).

\section{Availability of data and materials}

The datasets generated and/or analyzed during the current study are available from the corresponding author on reasonable request.

\section{Authors' contributions}

QQ was involved in data collection, case diagnosis and confirmation, and manuscript drafting for this article. YH obtained funding for this study and was involved in the conception, design, data interpretation, and data collection. WZ was involved in the data collection and case diagnosis and confirmation for this article. GZ was involved in the data collection and case diagnosis and confirmation for this article. QL was involved in the data collection and case diagnosis and confirmation for this article. XN was involved in data analysis, conception and design, data interpretation, and critical review for this article. JW was involved in the data analysis, conception and design, data interpretation, and critical review for this article. ZA obtained funding for this study and was involved in the conception and design, data interpretation, and critical review for this article. All authors read and approved the final manuscript.

Ethics approval and consent to participate

The study was approved by the ethics committee for medical research at Tianjin Huanhu Hospital, and written informed consent was obtained from each participant during recruitment.

\section{Consent for publication}

Not applicable

\section{Competing interests}

The authors declare that they have no competing interests.

\section{Publisher's Note}

Springer Nature remains neutral with regard to jurisdictional claims in published maps and institutional affiliations.

\footnotetext{
Author details

'Department of Neurology, Tianjin Huanhu Hospital, 6 Jizhao Road, Jinnan District, Tianjin 300350, China. ${ }^{2}$ Tianjin Key Laboratory of Cerebral Vascular and Neurodegenerative Disease, 6 Jizhao Road, Jinnan District, Tianjin 300350, China. ${ }^{3}$ Department of Epidemiology, Tianjin Neurological Institute, 154 Anshan Road, Heping District, Tianjin 300052, China. ${ }^{4}$ Department of Neurology, Tianjin Medical University General Hospital, 154 Anshan Road, Heping District, Tianjin 300052, China. ${ }^{5}$ Tianjin Neurological Institute, Key Laboratory of Post-Neuroinjury Neuro-repair and Regeneration in Central Nervous System, Ministry of Education and Tianjin City, 154 Anshan Road, Heping District, Tianjin 300052, China.
} 


\section{Received: 17 April 2018 Accepted: 27 July 2018}

\section{Published online: 02 August 2018}

\section{References}

1. Lloyd-Jones DM, Hong Y, Labarthe D, Mozaffarian D, Appel LJ, Van Horn $L$, et al. Defining and setting national goals for cardiovascular health promotion and disease reduction: the American Heart Association's strategic Impact Goal through 2020 and beyond. Circulation. 2010;121:586-613.

2. Lloyd-Jones D, Adams R, Carnethon M, De Simone G, Ferguson TB, Flegal K, et al. Heart disease and stroke statistics--2009 update: a report from the American Heart Association Statistics Committee and Stroke Statistics Subcommittee. Circulation. 2009;119:480-6.

3. Redon J, Olsen MH, Cooper RS, Zurriaga O, Martinez-Beneito MA, Laurent S, et al. Stroke mortality and trends from 1990 to 2006 in 39 countries from Europe and Central Asia: implications for control of high blood pressure. Eur Heart J. 2011;32:1424-31.

4. Ning $X$, Sun J, Jiang R, Lu H, Bai L, Shi M, et al. Increased stroke burdens among the low-income young and middle aged in rural China. Stroke. 2016:48:77-83.

5. National Health and Family Planning Commission of the People's Republic of China. China health and family planning statistics yearbook 2014. Beijing: China Union Medical University Press; 2015.

6. Lovett JK, Coull AJ, Rothwell PM. Early risk of recurrence by subtype of ischemic stroke in population-based incidence studies. Neurology. 2004; 62:569-73.

7. Purroy F, Montaner J, Molina CA, Delgado P, Ribo M, Álvarez-Sabín J. Patterns and predictors of early risk of recurrence after transient ischemic attack with respect to etiologic subtypes. Stroke. 2007;38:3225-9.

8. Kim BJ, Kim JS. Ischemic stroke subtype classification: an Asian viewpoint. J Stroke. 2014;16:8-17.

9. Banerjee S, Biram R, Chataway J, Ames D. South Asian strokes: lessons from the St Mary's stroke database. QJM. 2010;103:17-21.

10. Tsai CF, Thomas B, Sudlow CL. Epidemiology of stroke and its subtypes in Chinese vs white populations: a systematic review. Neurology. 2013;81:264-72

11. Kelly-Hayes M, Beiser A, Kase CS, Scaramucci A, D'Agostino RB, Wolf PA. The influence of gender and age on disability following ischemic stroke: the Framingham study. J Stroke Cerebrovasc Dis. 2003;12:119-26.

12. Di Carlo A, Lamassa M, Baldereschi M, Pracucci G, Basile AM, Wolfe CD, et al. Sex differences in the clinical presentation, resource use, and 3-month outcome of acute stroke in Europe: data from a multicenter multinational hospital-based registry. Stroke. 2003;34:1114-9.

13. Kapral MK, Fang J, Hill MD, Silver F, Richards J, Jaigobin C, et al. Sex differences in stroke care and outcomes: results from the registry of the Canadian stroke network. Stroke. 2005;36:809-14.

14. Niewada M, Kobayashi A, Sandercock PA, Kaminski B, Czlonkowska A. Influence of gender on baseline features and clinical outcomes among 17,370 patients with confirmed ischaemic stroke in the international stroke trial. Neuroepidemiology. 2005;24:123-8.

15. Reeves MJ, Bushnell CD, Howard G, Gargano JW, Duncan PW, Lynch G, et al. Sex differences in stroke: epidemiology, clinical presentation, medical care, and outcomes. Lancet Neurol. 2008;7:915-26.

16. Adams HP Jr, Bendixen BH, Kappelle LJ, Biller J, Love BB, Gordon DL, et al. Classification of subtype of acute ischemic stroke. Definitions for use in a multicenter clinical trial. TOAST. Trial of Org 10172 in Acute Stroke Treatment. Stroke. 1993;24:35-41.

17. Bamford J, Sandercock P, Dennis M, Burn J, Warlow C. Classification and natural history of clinically identifiable subtypes of cerebral infarction. Lancet. 1991;337:1521-6.

18. Kim J-S, Lee K-B, Roh H, Ahn M-Y, Hwang H-W. Gender differences in the functional recovery after acute stroke. J Clin Neurol. 2010;6:183-8.

19. Shin $D$, Lee $P$, Bang $O$. Mechanisms of recurrence in subtypes of ischemic stroke: a hospital-based follow-up study. Arch Neurol. 2005;62:1232-7.

20. Grau AJ, Weimar C, Buggle F, Heinrich A, Goertler M, Neumaier S, et al. Risk factors, outcome, and treatment in subtypes of ischemic stroke: the German stroke data bank. Stroke. 2001;32:2559-66.

21. Eriksson SE, Olsson JE. Survival and recurrent strokes in patients with different subtypes of stroke: a fourteen-year follow-up study. Cerebrovasc Dis. 2001;12:171-80.

22. Putaala J, Curtze $\mathrm{S}$, Hiltunen $\mathrm{S}$, Tolppanen $\mathrm{H}$, Kaste $\mathrm{M}$, Tatlisumak T. Causes of death and predictors of 5 -year mortality in young adults after first-ever ischemic stroke: the Helsinki Young Stroke Registry. Stroke. 2009:40:2698-703.

23. Staaf $G$, Lindgren A, Norrving B. Pure motor stroke from presumed lacunar infarct. Long-term prognosis for survival and risk of recurrent stroke. Stroke. 2001;32:2592-6.

24. Umemura T, Kawamura T, Umegaki H, Mashita S, Kanai A, Sakakibara T, et al. Endothelial and inflammatory markers in relation to progression of ischaemic cerebral small-vessel disease and cognitive impairment: a 6-year longitudinal study in patients with type 2 diabetes mellitus. J Neurol Neurosurg Psychiatry. 2011:82:1186-94.

25. Wu B, Lin S, Hao Z, Yang J, Xu Y, Wu L, et al. Proportion, risk factors and outcome of lacunar infarction: a hospital-based study in a Chinese population. Cerebrovasc Dis. 2010;29:181-7.

26. Jia Q, Zhao X, Wang C, Wang Y, Yan Y, Li H, et al. National Stroke Registry Diabetes and poor outcomes within 6 months after acute ischemic stroke: the China. Stroke. 2011;42:2758-62.

27. Sun Y, Paul M, Toh HS. Impact of diabetes mellitus (DM) on the health-care utilization and clinical outcomes of patients with stroke in Singapore. Value Health. 2009;12:S101-5.

28. Kaarisalo MM, Räihä I, Sivenius J, Immonen-Räihä P, Lehtonen A, Sarti C, et al. Diabetes worsens the outcome of acute ischemic stroke. Diabetes Res Clin Pract. 2005;69:293-8.

29. Appelros P, Nydevik I, Viitanen M. Poor outcome after first-ever stroke predictors for death, dependency, and recurrent stroke within the first year. Stroke. 2003;34:122-6.

30. German Stroke Study Collaboration. Predicting outcome after acute ischemic stroke: an external validation of prognostic models. Neurology. 2004:62:581-5.

31. Tanaka R, Ueno Y, Miyamoto N, Yamashiro K, Tanaka Y, Shimura H, et al. Impact of diabetes and prediabetes on the short-term prognosis in patients with acute ischemic stroke. J Neurol Sci. 2013;332:45-50.

32. Kong FY, Tao WD, Hao ZL, Liu M. Predictors of one-year disability and death in Chinese hospitalized women after ischemic stroke. Cerebrovasc Dis. 2010; 29:255-62.

33. Kissela BM, Khoury J, Kleindorfer D, Woo D, Schneider A, Alwell K, et al. Epidemiology of ischemic stroke in patients with diabetes: the greater Cincinnati/Northern Kentucky Stroke Study. Diabetes Care. 2005:28:355-9.

34. Kamalesh M, Shen J, Eckert GJ. Long term postischemic stroke mortality in diabetes: a veteran cohort analysis. Stroke. 2008;39:2727-31.

35. Callahan A, Amarenco P, Goldstein LB, Sillesen H, Messig M, Samsa GP, et al Risk of stroke and cardiovascular events after ischemic stroke or transient ischemic attack in patients with type 2diabetes or metabolic syndrome: secondary analysis of the Stroke Prevention by Aggressive Reduction in Cholesterol Levels (SPARCL) trial. Arch Neurol. 2011;68:1245-51.

36. González Hernández A, Fabre Pi O, López Fernández JC, Díaz Nicolás S, Cabrera HA. Risk factors, etiology and prognosis in patients with ischemic stroke and diabetes mellitus. Rev Clin Esp. 2008;208:546-50.

37. Tuttolomondo A, Pinto A, Salemi G, Di Raimondo D, Di Sciacca R, Fernandez $P$, et al. Diabetic and non-diabetic subjects with ischemic stroke: differences, subtype distribution and outcome. Nutr Metab Cardiovasc Dis. 2008;18:152-7

38. Gao Y, Jiang L, Wang H, Yu C, Wang W, Liu S, et al. Association between elevated hemoglobin A1c levels and the outcomes of patients with smallartery occlusion: a hospital-based study. PLoS One. 2016;11:e0160223.

39. Pan $Y$, Jing J, Li H, Wang $Y$, Wang $Y$, He $Y$. Abnormal glucose regulation increases stroke risk in minor ischemic stroke or TIA. Neurology. 2016;87:1551-6.

40. Koton S, Molshatzki N, Bornstein NM, Tanne D. Low cholesterol, statins and outcomes in patients with first-ever acute ischemic stroke. Cerebrovasc Dis. 2012;34:213-20.

41. Zhao W, An Z, Hong Y, Zhou G, Guo J, Zhang Y, et al. Low total cholesterol level is the independent predictor of poor outcomes in patients with acute ischemic stroke: a hospital-based prospective study. BMC Neurol. 2016;16:36.

42. Amarenco P, Lavallee P, Touboul P-J. Stroke prevention, blood cholesterol, and statins. Lancet Neurol. 2004;3:271-8.

43. Amarenco $P$, Moskowitz MA. The dynamics of statins: from event prevention to neuroprotection. Stroke. 2006;37:294-6.

44. Lavallée PC, Labreuche J, Gongora-Rivera F, Jaramillo A, Brenner D, Klein IF, et al. Placebo-controlled trial of high-dose atorvastatin in patients with severe cerebral small vessel disease. Stroke. 2009:40:1721-8. 